\title{
Desigualdade Social: Significações de Prounistas do curso de Psicologia da PUC-SP
}

\author{
Social Inequality: The Significations of Prounistas Psychology \\ students from PUC-SP
}

\author{
Marcos Martins Amaral' ${ }^{1}$, Renata Paparelli ${ }^{2}$ \\ 1'Autor para correspondência. Pontifícia Universidade Católica de São Paulo. São Paulo, São Paulo, Brasil. \\ ORCID: 0000-0001-5621-2991. amaral.m.marcos@gmail.com \\ ²Pontifícia Universidade Católica de São Paulo. São Paulo, São Paulo, Brasil. ORCID: 0000-0002-4925-5771.rpaparel@uol.com.br
}

\begin{abstract}
RESUMO | A desigualdade social expressa-se, dentre outros modos, na dificuldade de acesso ao ensino superior. Medidas compensatórias e de ações afirmativas foram um avanço na medida em que abriram espaço para que negros(as) e periféricos(as) pudessem ocupar os bancos universitários. O objetivo deste trabalho foi analisar e compreender as experiências, percepções e sentidos subjetivos constituídos por discentes bolsistas do Programa Universidade para Todos (ProUni) do curso de Psicologia da Pontifícia Universidade Católica de São Paulo (PUC-SP) resultantes do encontro das estudantes pobres com a Universidade, local em que diferentes classes sociais se encontram. Destacamos a dimensão subjetiva do fenômeno, trazendo a realidade (objetividade) para a constituição da subjetividade, numa tentativa de superar as teorias objetivistas e subjetivistas, apropriando-nos do materialismo histórico dialético e da Psicologia Sócio-Histórica. Foram realizadas conversações para a produção de dados com duas prounistas que estavam cursando o quinto ano do referido curso em 2016. As falas foram compreendidas e analisadas à luz da desigualdade social, a partir da proposta de análise dos Núcleos de Significação. O movimento dialético de análise nos permitiu explicitar os sentidos subjetivos - doloridos e potentes - das graduandas no encontro desigual com a universidade, que produziu reposicionamentos importantes de existência e resistência.
\end{abstract}

PALAVRAS-CHAVE: Fatores socioeconômicos. Educação superior. Subjetividade.

\begin{abstract}
Social inequality is expressed, among other ways, in the difficulty of access to higher education. Compensatory and affirmative action measures were an advance in that they made room for blacks and peripherals to occupy university banks. The objective of this work was to analyse and understand the experiences, perceptions and subjective meanings made up of scholarship students from the University for All Program (ProUni - of the initials in Portuguese) of the Psychology course of the Pontifical Catholic University of Sao Paulo (PUC$\mathrm{SP}$ - of the initials in Portuguese) resulting from the meeting of poor students with the University, where different social classes meet. We emphasize the subjective dimension of the phenomenon, bringing reality (objectivity) to the constitution of subjectivity, in an attempt to overcome objectivist and subjectivist theories, appropriating us from dialectical historical materialism and Socio-Historical Psychology. Talks were held for the production of data with two scholarship students from ProUni who were attending the 5th year of said course in 2016. The speeches were understood and analysed in the light of social inequality, based on the proposal of analysis of the Nuclei of Meaning. The dialectical movement of the analysis has allowed us to explicit the subjective senses painful and powerful - of the undergraduates in their unequal encounter with the university, that produced important shifts in their understanding of existence and resistance.
\end{abstract}

KEYWORDS: Socioeconomic factors. Superior education. Subjectivity. 


\section{Introdução}

A desigualdade social é marca estruturante da realidade brasileira e sua expressão é múltipla e complexa (Guerra, Pochmann, \& Aldrin, 2015; Souza, 2004, 2006). Interessando-nos, no presente trabalho, a dimensão educacional, especialmente no que se refere ao ingresso ao ensino superior. Dados da Pesquisa Nacional por Amostra de Domicílios - PNAD (2014) mostram que os ricos estudam em média 12 anos e os mais pobres, 8,2 anos. Vale destacar que a desigualdade de acesso é estruturada pelo racismo: negras e negros são sobrerrepresentados nas classes mais pobres e sub-representados nas classes mais ricas (Nascimento, 2017). Portanto, políticas públicas que favoreçam o acesso das populações mais pobres aos níveis de ensino mais elevados são sobremaneira importantes nessa realidade.

Em 2003, assume a presidência, com grande apoio popular, Luís Inácio Lula da Silva. Em sua gestão, reformas importantes no que tange ao ensino superior foram realizadas. Pode-se mencionar o Sistema Nacional de Avaliação do Ensino Superior (SINAES), a ampliação do Programa de Financiamento Estudantil (FIES), o Programa de Apoio a Planos de Reestruturação e Expansão das Universidades Federais (REUNI), dentre outros (Barros, 2015). O presente artigo, fruto de pesquisa de conclusão do curso de Psicologia da Pontifícia Universidade Católica de São Paulo (PUC-SP), tem como foco uma das ações do governo federal para este nível de ensino, o Programa Universidade Para Todos (ProUni), sancionado pela Lei no 11.096, de 13 de janeiro de 2005.

Houve um contraditório e intenso jogo político em torno do projeto de lei que viria a instituir o Programa. Esse foi pressionado por uma série de atores: pelas empresas privadas de Ensino Superior e suas associações representativas, cujo objetivo é mercantilizar a educação brasileira; pela sociedade civil e movimentos organizados, como União Nacional dos Estudantes (UNE), que defendem a democratização de acesso a este nível de ensino; pelas instituições públicas de educação, críticas ao PROUNI, na medida em que o projeto utiliza recursos públicos na iniciativa privada em detrimento do investimento em expansão e fortalecimento das Instituições de Ensino Superior Públicas Federais (Catani, Hey e Giglioli. 2006; Carvalho, 2006).
O ProUni inseriu-se numa realidade em que, segundo dados do Censo da Educação Superior (INEP, 2003), 88,9\% das Instituições de Ensino Superior (IES) no Brasil eram privadas, concentrando a maior disponibilidade de vagas. Além disso, em 2001, menos de $12,0 \%$ dos jovens brasileiros de 18 a 24 anos estavam matriculados em IES. O ProUni concede bolsas de estudos a estudantes pobres em IES privadas através da nota no Exame Nacional do Ensino Médio (ENEM), configurando-se como medida compensatória e também como política de ação afirmativa, na medida em que reserva vagas para pretas(os), pardas(os) e indígenas.

O Programa recebe críticas acerca da possiblidade de queda de qualidade na Educação Superior, já que, em geral, os bolsistas provem de escolas públicas, portanto com possível defasagem educacional e teriam dificuldades em acompanhar seus pares provenientes das escolas particulares (Nogueira, 2013). Pesquisas sobre rendimento acadêmico dos bolsistas prounistas aponta que esses apresentam rendimento escolar equivalente aos alunos ingressantes pelo tradicional sistema de vestibular. (Costa, 2010)

Muitos estudos que investigam a desigualdade social são feitos no Brasil, estudos nos planos econômico, sociológico, jurídico. Porém, a grande maioria das investigações acerca do fenômeno tem abandonado a sua dimensão subjetiva, os estudos acabam por não olhar para as pessoas que produzem e são produzidas pela realidade social desigual; para aqueles que vivem cotidianamente a expressão da desigualdade; isso acaba por levar a um descolamento do fenômeno da realidade. (Bock, 2010; Souza, 2006)

Compreendendo o caráter desigual da sociedade e a presença de um corpo estudantil, no curso de Psicologia da PUC-SP, pertencente majoritariamente a segmentos ricos da população; o objetivo do presente trabalho foi analisar e compreender os sentidos subjetivos produzidos na trajetória universitária de graduandas pobres do curso de Psicologia da PUC-SP, que obtiveram acesso ao curso via política pública, a saber, ProUni.

Em síntese, o objetivo do trabalho foi compreender os sentidos produzidos pelas graduandas na universidade, suas contradições e a forma como ele se expressa concretamente numa instituição elitizada. Explicitar os sentidos subjetivos produzidos a partir dos aspectos objetivos, concretos da vida social deste 
encontro de desigualdade cotidiano, incorporando “(...) a dialética entre objetividade e subjetividade, no esforço para articular o sujeito com seu processo social e histórico". (Santos. 2013. p 52)

\section{Método}

Este trabalho apoia-se no referencial teórico metodológico da Psicologia Sócio-Histórica, partindo de uma noção materialista, histórica e dialética da realidade, num esforço para superar as teorias subjetivistas e objetivistas do campo psicológico, que acabam naturalizando os fenômenos. Compreendendo que a realidade é produzida por um sujeito histórico que é ativo, indivíduo e sociedade estão em movimento num processo dialético. O fenômeno psicológico é aqui entendido como construção no nível individual do mundo simbólico, que é social, e a subjetividade, concebida como algo que se constitui na relação com a objetividade, no mundo material que só existe pela atividade do homem. (Bock, 2015)

Assim, optamos por realizar conversação (González Rey, 2010) para produção de informação, com duas protagonistas do ProUni, "prounistas" que estavam cursando o quinto ano do curso de Psicologia na PUC-SP no primeiro semestre de 2016. Para isso enviamos e-mail contatando todas as prounistas do curso de Psicologia da PUCSP que estavam cursando este período em 2016, convidando para que participassem da pesquisa, das que responderam ao e-mail sorteamos duas estudantes.

A decisão por alunas do quinto ano do curso se deu porque estas graduandas ficaram por um período longo na Universidade, o que dá maior apropriação no que tange à apreensão do curso, bem como na construção das relações com outros colegas. A conversação foi realizada com Amora e Alice (nomes fictícios).

Amora tem 24 anos, é mulher e negra. Estendeu sua formação em um ano, porque trancou algumas disciplinas quando estava no quarto ano - a grade curricular normal do curso de Psicologia da PUCSP dura cinco anos ou dez semestres - , segundo ela para que pudesse aproveitar melhor a graduação; Alice tem 23 anos, é mulher, branca e militante de um movimento social de juventude. Seguiu a grade curricular normal do curso.
A conversação convoca o pesquisador a integrar-se na dinâmica conversacional produzida pelo encontro e a responsabilizar-se pelo tecido de informação produzida, deixando de ser um centro disparador de perguntas. A conversação, portanto, responsabiliza pesquisador e os participantes da pesquisa do movimento de produção de informação. (González Rey, 2010).

É no processo de comunicação que o outro se envolve em suas reflexões e emoções sobre os temas que vão aparecendo, e o pesquisador deve acompanhar, com o mesmo interesse, tanto o envolvimento dos participantes como os conteúdos que surgem. A pessoa envolvida no sistema conversacional evidencia esse envolvimento durante a conversação. Envolvimento muito importante para a pesquisa, pois dele dependerá a qualidade da informação obtida por tal via. (González Rey, 2010, p. 47)

A pergunta disparadora - nesse processo ativo entre o pesquisador e pesquisadas - foi "como está sendo sua experiência de aluna prounista na graduação do curso de Psicologia da PUC-SP?". Tal questão visou a abrir espaço para múltiplas expressões das graduandas, incorporando "a dialética entre objetividade e subjetividade, no esforço para articular o sujeito com seu processo social e histórico". (Santos, 2013, p. 52)

O movimento de análise das conversações foi inspirado nos Núcleos de Significação, proposta desenvolvida por Aguiar e Ozella (2006; 2013) e Aguiar, Soares e Machado (2015) à luz da desigualdade social. Compreendemos que há nesse procedimento compromisso ético-político, na medida em que "(...) uma das marcas desse tipo de análise é ter como meta desvelar fatos e fenômenos, explicitar contradições e assim, ousar apontar caminhos mais críticos, menos naturalizantes e ideológicos". (Aguiar e Ozella, 2006, p. 243)

O procedimento de análise seguiu um movimento que partiu de leituras flutuantes do material, passando a pré-indicadores, indicadores e, finalmente, os Núcleos de Significação. Foi um movimento dialético de análise, um procedimento que caminhou em espiral, no qual, por exemplo, o primeiro momento de leitura exaustiva do material nos acompanhou até a finalização da análise. O material completo foi lido sempre e em todo o movimento. As outras partes do espiral (pré-indicadores, indicadores, Núcleos) surgiram no movimento do procedimento. O processo de configuração dos Núcleos de Significação deu-se, 
coerente com Aguiar e Ozella (2006; 2013) e com Aguiar, Soares e Machado (2015), a partir de nossa compreensão crítica da realidade. Assim, buscou-se explicitar os sentidos e significados constituídos no confronto com a realidade, os quais, após o movimento de análise, ofereceram elementos acerca da dimensão subjetiva da realidade.

As conversações foram analisadas conjuntamente, o que permitiu uma análise mais ampla do encontro das graduandas, e, apesar de suas singularidades, o que se destacou em nossos encontros foram suas aproximações, seja por singularidade, complementaridade ou contradição. Para além disso, foi nesse encontro que a compreensão do fenômeno foi aparecendo para nós e, por isso, é deste modo que ela deve aparecer ao leitor.

Fizemos um esforço de trabalhar com o fenômeno social desigualdade social a partir de sua complexidade, sem perder de vista a realidade social e as pessoas que constroem e são construídas por essa realidade que muitas vezes é naturalizada. A ação do sujeito no mundo nos permite afirmar que a realidade social é construída historicamente, tem base material e contém subjetividade.

Acreditamos, juntamente com Bock (2010), que precisamos compreender a desigualdade além do plano econômico para que possamos enfrentá-la para superá-la. Olhamos, portanto, para a objetividade e subjetividade como unidade de contrários e de movimento constante de transformação. A dimensão subjetiva da realidade representa um processo dialético entre a objetividade e a subjetividade e as experiências subjetivas dos fenômenos. O sujeito individual é determinado pelo que encontra na realidade, mas também sujeito ativo de transformação. Apreendemos a dimensão subjetiva da desigualdade social a partir da categoria contradição, com o pensamento dialético e a noção de historicidade, utilizando-nos da Psicologia com compromisso social ético-político e olhando para um determinado projeto de sociedade que acredita que, para avançarmos, precisamos apontar a desigualdade de modo crítico e não naturalizado, percebendo as contradições que a envolvem, sempre com vistas a sua superação.

A presente pesquisa foi submetida e aprovada pelo comitê de ética e pesquisa sob o Parecer $n^{\circ}$ 1.403.948. E registrado na Plataforma Brasil sob o CAAE 52495015.8.0000.5482.

\section{Resultados e Discussão}

O movimento da análise das conversações permitiu aglutinar o material em quatro núcleos de significação, a saber: (R)Existindo no encontro desigual encontrando os iguais; a marca da desigualdade é explícita; a pobreza exótica: eles não sabem o que é baile de favela; reinventando meu lugar: nem tão periférica, nem tão Perdizes.

\section{(R)Existindo no encontro desigual encontrando os iguais}

Este núcleo diz respeito a significações dos vieses vividos pelas alunas no encontro com a desigualdade. Ele reuniu os seguintes indicadores: encantamento com a universidade; desencantamento com a universidade: primeiros momentos de humilhação; ProUni e permanência; acolhimento com os iguais.

Ao ingressar na Universidade, a desigualdade social já se realiza no primeiro momento para as duas graduandas. Amora diz que ficou muito feliz quando descobriu que havia passado na universidade, no curso que almejava. Mas isso durou pouco:

Mas a felicidade durou relativamente pouco, porque aí eu descobri que tem que levar documento disso e daquilo... tudo bem, vamos lá, corri atrás de tudo [...] E agora? Ah, eles vão investigar sua vida, vão investigar sua casa, vão investigar o que você come, a roupa que você usa... (Amora).

Amora está se referindo ao processo de apresentar a documentação comprobatória, conforme referido na Lei $n^{\circ} 11.096 / 2005$, de que ela não tinha possibilidades de pagar as mensalidades do curso e de que ela estava no perfil do programa. Em suas palavras:

Eu e minha família começamos a nos sentir muito humilhados por causa desse processo de investigação. Teve um dia que meu pai falou assim 'Filha, sabe o que eu queria? Ter dinheiro pra poder pagar esse negócio pra não precisar passar por isso' (Amora).

Além disso, ela aponta a falta de acolhimento dos examinadores da documentação:

Eu cheguei aqui, trouxe a documentação, a examinadora pegou meus documentos, olhou o valor da minha conta de luz e disse "por que vocês gastam tudo isso? Se o valor for esse já tô te avisando, você não vai conseguir a bolsa", isso no primeiro dia, 
quando eu vim trazer os documentos. Eu fiquei mais desesperada ainda (Amora).

As graduandas ressaltaram que as prounistas se matriculam depois das alunas pagantes, ingressando no curso com o semestre letivo em andamento. Elas explicitam o incômodo de, ao ingressarem, se depararem com grupos formados, com parte das disciplinas já tendo sido ministradas, o que faz com que tenham que "correr" para acompanhar a turma. Não à toa, Alice compara esse primeiro momento ao Mississipi, estado norte-americano conhecido por ser racista e ter extremos índices de desigualdade, um estado em que pobres e ricos estão geograficamente ocupando lugares opostos.

Porque ProUni tem que entrar mais tarde? Assim, eu já não queria vir porque eu não sabia o que era o ProUni, aí me jogam depois das pessoas, quando os grupos estão formados. A gente pega o conteúdo atrasado muito rapidamente, corre atrás. Acho que entrei um mês depois. É horrível a sensação de que todo mundo tá caminhando e você tem que correr. [...] Você vem de uma realidade muito outra, muito distante daqui [...] você ser restringido à sua possibilidade de interação tem efeitos muito grandes que podem levar à desistência, não ter o contorno universitário, isso tem efeitos. Eu acho que a gente tem que ser colocado nos mesmos lugares, isso não é o Mississipi (Alice).

Sobre entrar após os alunos pagantes, corroborando com Alice, Amora diz:

Então já é completamente diferente porque a gente não tem aquele primeiro dia do trote, aquele acolhimento... eu simplesmente caí aqui de paraquedas. [...] Já começa a ser uma marca, não uma exclusão, mas uma marca.

Você não passa pelos rituais [...] de apresentação à Universidade. E não é só que você entra depois, você entra jogado (Amora).

As desigualdades seguem aparecendo ao longo da graduação, as falas de Alice e de Amora denunciam uma deficiência concreta do programa, a permanência. Excetuando um programa da própria universidade, o Programa de Atendimento Comunitário (PAC), as estudantes não contam com nenhuma forma de apoio do ProUni no que tange à permanência. Nesse sentido, explicitam: "Se for alguém muito, muito pobre, ela não vai conseguir se sustentar aqui dentro, porque os gastos são muito caros" (Amora).
O que é uma falha do ProUni ainda, e é uma crítica que eu tenho, é não garantir a permanência do prounista, porque te joga numa universidade como a PUC que tem um curso maluco, que você vai pra um lado e pro outro e não te dá nenhuma assistência ao não ser um PAC, se você quiser alguma bolsa tem que entrar num programa de extensão... (Alice).

Mas, além da explicitação da desigualdade, do sentimento de estarem "perdidas num mundo novo", houve espaços de acolhimento, troca e reconhecimento no outro, especialmente no outro também prounista. Ambas graduandas falam sobre o acolhimento e a importância que outras prounistas tiveram nesse primeiro momento, bem como do coletivo auto-organizado de prounistas da PUC-SP, o ProUni-se. Parece que a existência do coletivo fortaleceu as graduandas e as auxiliou no processo de apropriação do seu lugar de estudante e de coletividade.

Mas tem, o que eu acho rico da PUC, que foi o movimento dos prounistas da PUC de criar o ProUni-se, pra tentar dar um acolhimento e suprir coisas que a gente passou para que os futuros prounistas não passem (Amora).

Esse coletivo foi importante pra saber quem poderia ajudar caso alguma coisa acontecesse, algum preconceito, discriminação, alguma questão institucional. É um coletivo com pessoas que conhecem a política do ProUni e isso favorecia essa troca mais aberta... isso é importante pro prounista, ter um espaço pra se apropriar da política. [...] Naquele momento

o ProUni-se foi importante pra me dizer "vamos nos unir", que eu não estava sozinha, que tinha um monte de gente aqui que era da periferia (Alice).

A expressão forte da desigualdade ao longo de sua trajetória na graduação as solicitou que resistissem para permanecerem, e encontraram espaços de fortalecimento que as ajudaram, destacando-se o coletivo ProUni-se, reconhecendo que nos iguais foram acolhidas.

\section{A marca da desigualdade é explícita}

Esse núcleo aglutinou os seguintes indicadores: a marca prounistas; racismo e privilégio branco; expressões da desigualdade; universidade e suas contradições. 
Alice é branca e Amora é preta, e as questões raciais apareceram de formas diferentes para as duas, mesmo ambas sendo mulheres, periféricas, prounistas. Alice afirma que, por ser branca, "não tem cara de prounista", às vezes, consegue passar despercebida enquanto bolsista.

Acho que aí a gente está falando de questões de raça, da questão racial, eu acho que tem um consenso de que quem é periférico é negro [...] quando eu fui parar pra pensar nos meus colegas prounistas, eu vi que eu me distinguia muito delas, meu cabelo não é crespo, minha pele não é negra, eu sou a branca das brancas [...] as pessoas ficavam muito chocadas quando descobriam que eu era prounista... (Alice).

Para Amora, ser mulher negra já a marca, num lugar com maioria branca:

Eu cheguei na PUC superuniformizada, a pessoa me olhava e falava que eu era prounista. Obviamente, hoje, as pessoas sabem que eu sou prounista, porque eu sou negra e as pessoas sabem que não existem muitas pessoas negras pagando aqui na faculdade.

Espero que as pessoas suponham por aí, não vou me incomodar (Amora).

Alice reconhece que ser branca a coloca num lugar privilegiado, mas ela só se deu conta disso na Universidade, porque: "Todo mundo que eu converso na periferia é negro, minhas amigas de cursinho são negras, e meu pai é negro, meu irmão é negro. Foi uma coisinha de nada, que a gente nem enxerga, mas no DNA... e isso, ser branca me trouxe tantos privilégios" (Alice).

Embora uma seja branca e a outra seja negra, para ambas, a pobreza é uma marca ímpar, que as aproxima do grupo de prounistas e as distancia dos demais estudantes.

[...] de não saber o que eles conversavam, de não ter ideia. Eu lembro deles falando de lugares que eles foram, de comidas que eles comeram, de bebidas que eles tomaram. Como você se envolve em conversas deste tipo se você não sabe do que eles estão falando? [...] Eu nunca viajei, não tenho carro, não vou pra balada todo final de semana porque eu não tenho dinheiro pra isso, não tô no bar sempre porque eu não tenho dinheiro pra isso... (Alice).

As pessoas que estudaram no mesmo colégio estão aqui, eu não tenho ninguém, é muita marca...
Tem marcas que dizem "Você é diferente" e eu não acho que isso seja ruim, eu acho ruim só eu ser a diferente aqui, sabe? (Amora). Ser "a única diferente" é algo que vem se transformando devido à ampliação das políticas públicas de acesso ao ensino superior no Brasil, ao longo dos últimos 14 anos. "Tem muito mais meninas negras nos anos subsequentes do que no meu, e isso é muito da hora" (Amora).

Muita coisa mudou fora do âmbito São Paulo. Acho que São Paulo sempre foi aquela coisa: filho dos ricos vai pra universidade, filho do pobre termina o ensino médio e vai pro subemprego. E nesse sentido

São Paulo já mudou e imagina em outros lugares, você começa a ir pra capital e não é só o filho do rico que vai pra capital agora porque as federais têm políticas de permanência (Alice).

Existem diferenças que explicitam o encontro desigual com a PUC-SP, que se expressam através de desigualdades concretas, físicas, financeiras. Esses fatores, bem como a ampliação das políticas de acesso à universidade, foram importantes para que elas pudessem refletir sobre o lugar potente que ocupam estando na universidade e no curso de Psicologia da PUC-SP.

\section{A pobreza exótica: eles não sabem o que é baile de favela}

Esse núcleo explicita os sentidos e significados presentes nas falas das estudantes acerca da percepção que os ricos têm sobre a vida na pobreza e das políticas públicas voltadas a essa população. Para tanto, aglutinou os indicadores: quando eles falam de nós; o rico (des)encontra a periferia.

As graduandas revelam perceber uma enorme distância social presente na separação entre ricos e pobres. Um dos cenários que elas destacam refere-se ao interior dos muros da Universidade:

Eu vejo a galera dançando baile de favela dentro dos portões protegidos da PUC e, velho, eles não sabem o que é baile de favela. Nem eu sei o que é um baile de favela, eu que tô ali do lado, colada, nunca fui num baile de favela, sabe? (Amora).

Ao mesmo tempo eu não sou totalmente baile de favela, mas é uma apropriação da vida do outro. Acho que os alunos se apropriam da pobreza, é louco isso,

mas é legal ser pobre, é legal ser preto, é legal ser mulher... porque é legal ser minoria? (Alice). 
"Baile de favela" faz referência a uma música que ficou famosa na voz do MC João, na qual ele cita bairros da periferia de São Paulo. A música tem um tom de exaltação à favela e às periferias da cidade. As graduandas afirmam que as alunas da PUC-SP se apropriaram disso de um jeito que as incomoda, porque a música, para elas, perde sentido quando toca em um bairro rico.

A desigualdade social por vezes é ou foi tema do curso de Psicologia. As meninas se aborrecem com a forma como o tema é dito, discutido, abordado em sala de aula, principalmente com os ricos falando da pobreza ou de políticas públicas: "Me incomodava quando as pessoas falavam da escola pública, porque falavam como se fosse tão distante, o que é na verdade, mas falavam de um jeito muito abstrato [...] porque chega a ser até exótico, e me incomoda" (Amora).

Alice traz um incômodo muito parecido, mas explicita isso dando exemplo dos estágios obrigatórios que ocorrem na Soweto (nome fictício), um território majoritariamente pobre, localizado na Zona Norte da cidade de São Paulo.

Em estágio realizado na Soweto, com adolescentes em medida socioeducativa, Amora relata que, num determinado momento, os adolescentes estavam com dificuldades em falar sobre drogas com os estagiários. Em sua análise, essa dificuldade se relacionava com a distância entre as realidades vividas pelos estudantes ricos da universidade e os estudantes pobres da periferia.

Alguns estagiários falaram que eles sabiam sim o que era aquilo e porque eles também usam drogas no $C A$, por exemplo e etcetera... E aquilo pra mim não fez o menor sentido, porque é isso, uma coisa é você usar maconha aqui no CA [centro acadêmico], outra coisa é você ser espancando pelo policial porque tava com maconha no bolso, sabe? (Amora).

Alice entende que o Soweto é percebido pelos estudantes pagantes como uma espécie de zoológico:

E zoológico porque você não sabe que pessoas estão lá e é uma exposição total das pessoas que estão lá. Eu fui no zoológico algumas vezes e ver os macacos era muito engraçado porque nem sempre eles estavam disponiveis pra gente e a gente ia lá só pra isso. É zoológico porque é algo que você não vive, você vai lá só pra ver, como que é, como vivem, como se comportam, e se surpreendem porque reconhecem que são seres humanos. Sabe que uma vez escutei uma colega voltando da Soweto dizendo que queria fazer um ensaio fotográfico na Soweto. Deu um desconforto e eu fiquei na minha imaginação, por que querer fazer um ensaio lá? Por que é diferente, é excêntrico, é exótico, vai ser cool pros seus amigos... (Alice).

Alice afirma que há, por parte do corpo docente, um reconhecimento dos alunos que fazem estágio na Soweto, uma exaltação porque sua formação foi para além dos muros da Universidade, como se eles viessem a se tornar profissionais diferenciados devido a essa experiência. Nesse sentido, ironiza:

Os alunos pagantes que estão indo pra Soweto são tão maravilhosos em sala de aula... porque eles falam de pobreza, olha só, eles trazem essa dimensão que é pobre, e às vezes eles trazem essa dimensão como se estivessem falando de um zoológico.

Tipo 'Ele não me assediou. Ele me deu cafezinho. Essa moradora foi simpática' (Alice).

Falar sobre a realidade, num país majoritariamente pobre, preto e periférico, num curso majoritariamente rico, branco e elitista, parece transformar-se em virtude. Existe, portanto, um preconceito contra os segmentos pobres que se expressa, em sua grande maioria, de forma velada nos estágios e nas relações dentro da universidade.

Simultaneamente, Alice ressalta a importância dos estágios serem na periferia da cidade: “Eu acho muito importante ser na Soweto. Isso é bem marcado pra mim, há muito tempo eu vejo que o papel da Universidade é se voltar pra sociedade, minimamente os estágios têm que servir à sociedade" (Alice).

Em síntese, esse núcleo destacou aspectos percebidos pelas depoentes que apartam as compreensões de pobres e ricos, inclusive em processos de trabaIho, como nos estágios. Ao mesmo tempo, destacam que a experiência de ir à periferia pode e deve ser estimulada, tendo em vista a contribuição social da universidade.

\section{Reinventando meu lugar: nem tão periférica, nem tão Perdizes}

Os indicadores que foram aglutinados nesse núcleo foram: direitos ou privilégios?; o meu "não lugar". É importante destacar que Perdizes é em referência a um bairro nobre da cidade de São Paulo. 
Amora e Alice habitam simultaneamente dois espaços sociais: o bairro rico e a periferia. Essa passagem de um lugar a outro produz marcas importantes em suas trajetórias e as convoca a constituir novos sentidos para essa experiência. É como se elas não fossem nem tão pobres para estarem com os pobres, nem tão ricas para estarem com os ricos.

Quando eu imagino periferia eu imagino casas muito juntas, e aqui imagino vários prédios. E é muito viva essa interação de escutar o que tá acontecendo na casa do vizinho. E aí eu não me encaixo nesse vizinho, sabe? Mas também não moro em prédio. E nessa interação eu vou me construindo, o que é muito rico pra mim e é muito desgastante ao mesmo tempo, muito desgastante (Alice).

Isso as coloca no que elas chamaram de "não lugar" ou "limbo": "Às vezes, eu me sinto num limbo, num buraco" (Amora).

Porque elas precisam lidar e se (re)construir sendo atravessadas pelos dois espaços (periferia e Perdizes), que fazem parte de suas vidas objetivamente, cotidianamente, e elas aceitam o desafio de lidar com isso e se (re)organizar no meio dessas diferenças, se fazer na presença constante da desigualdade.

Tem momentos que eu me sinto totalmente universitária, tomar cerveja no bar, fumar um beck, fumar um cigarro e discutir Marx, que é o cúmulo do universitário de humanas, e eu me vejo ali na periferia tendo que pegar metrô lotado ou tendo que ouvir o grito do meu vizinho com o filho pequeno porque eles vivem numa casa muito pequena, trabalha o dia inteiro, o que gera um estresse muito grande, sabe essas coisas assim? (Alice).

Sentir-se nesse "não lugar" vai gerando transformações e reflexões:

Mesmo não estando nem lá e nem aqui, ainda assim eu posso estar em vários lugares, mesmo não tendo esse contorno de ser só periférica ou só

Perdizes. Eu transito e isso vai me gerando uma identidade, [...] o não lugar é uma sensação incômoda, só que isso diz do que você é, de que você tá sendo atravessado por muita coisa, que você tá sendo bombardeado... todo o tempo você tem que se deparar com o cobrador que é seu vizinho, você tem que se deparar com o professor, que por mais que você queira

traçar uma trajetória muito parecida com a dele vai ser muito difícil, porque ele vem desse outro lugar que não é seu, sabe? Esses não lugares falam de um existir muito conflituoso, muito cheio,um existir que pode proporcionar muitos benefícios praesses lugares diferentes (Alice).

Durante a conversação, tivemos a oportunidade de refletir sobre privilégios e direitos, na medida em que elas afirmam serem privilegiadas por acessarem direitos, como por exemplo, frequentar o ensino superior.

Eu não vejo que está sendo tratado como direito hoje. Por mais que esteja no papel que é um direito, não é um direito garantido porque poucas pessoas acessam ele, e as pessoas têm traços que as privilegiam, porque eu acesso e a minha vizinha não? Se tivemos trajetórias de vida parecidas? Porque não é mérito, eu cabulava aula igual ela, sabe? (Alice).

Eu comecei a ver um monte de privilégios meus que não era pra ser privilégio, era pra ser direito, era pra

ser normal. Eu comecei a ver como privilégio meus pais olharem meus cadernos quando eu era criança. Comecei a ver como privilégio minha mãe ter tempo de ir às minhas reuniões de escola (Amora).

Um direito, quando negado para uns, reveste-se de privilégio para outros. Entender o acesso ao ensino superior enquanto privilégio também pode ter relação com a posição de prestígio social que elas enxergam ter frente às pessoas de seu território de origem, com as diferenças que enxergam quando olham para pessoas de sua mesma classe social, com seus vizinhos e amigos que não estão na universidade. Sobre a relação entre acesso ao ensino superior e privilégios, Alice explicita "A questão é que eu acessei e outras pessoas não, e é isso que me incomoda, me faz entender que eu sou privilegiada" (Alice).

O prestígio social, a possibilidade de estar na PUC-SP, o fato de se sentirem privilegiadas ante a periferia, as faz perceberem um distanciamento do território de origem. Por outro lado, a questão privilégio versus direitos sofre uma inversão quando elas se deparam com a realidade universitária.“O que é privilégio lá, aqui é natural, nada do que é privilégio lá, aqui é, nada. Há uma inversão" (Amora).

As condições consideradas privilegiadas no lugar de origem, como vimos, são "naturais" no bairro rico. $\mathrm{E}$ um novo deslocamento se instala, as "privilegiadas" da perspectiva da periferia tornam-se novamente as "excluídas" no bairro rico, sendo alijadas das possibilidades de frequentarem espaços de socialização 
importantes para além da sala de aula, como o centro acadêmico, as festas universitárias...

Mas tem uma questão do CA, de chegar num momento e eu achar que aquele espaço não me representa, de eu não me sentir pertencente àquele espaço, de entrar e me apropriar. No segundo, terceiro ano da faculdade quando eu compartilhei isso com outras colegas prounistas, elas falavam que elas também, nem bar, nem $C A$, nem festa, nem nada (Amora).

O CA é o espaço por excelência de socialização e de discussões políticas ao qual as depoentes não se sentem pertencentes. Mesmo Alice sendo militante de um movimento social, ela atesta o seu não reconhecimento no movimento estudantil da PUC-SP.

Em síntese, a experiência da passagem pela universidade no bairro rico traz consigo a possibilidade de construir pontes entre a periferia e o centro, entre pobres e ricos. Um desafio coloca-se pra elas, o de reinventar seu lugar, para si e para o mundo. Elas são pobres em um espaço de elite, o que as afasta e as aproxima de um mundo desconhecido, em que procuram reconhecer-se.

\section{Considerações finais}

Compreendendo que a desigualdade social tem uma dimensão subjetiva (Bock, 2010; Santos, 2013), fizemos um esforço para analisar os sentidos subjetivos que estudantes prounistas do curso de Psicologia da PUC-SP atribuem à sua experiência na trajetória universitária: "a realidade da desigualdade social que marca a sociedade brasileira está constituída também por uma dimensão subjetiva de sentimentos, significados, afetos, valores, enfim, registros simbólicos e afetivos que caracterizam o fenômeno" (Bock, 2010, p. 15).

Os governos Lula (2003-2010) e Dilma (2011-2016) tiveram um efeito histórico no que tange ao investimento e à ampliação de vagas no ensino superior, o que contou com a influência direta do protagonismo que os movimentos sociais tiveram nessa empreitada. Com todas as contradições, foi nesse período que o ProUni foi criado e ampliado (Sader, 2013).
Inspirados na proposta metodológica de Aguiar e Ozella (2006; 2013) e Aguiar, Soares e Machado (2015), nosso movimento dialético de análise aglutinou quatro núcleos de significação: (r)existindo no encontro desigual encontrando os iguais; a marca da desigualdade é explícita; a pobreza exótica: eles não sabem o que é baile de favela; nem tão periférica, nem tão Perdizes.

Em síntese, a trajetória marcada pela desigualdade social solicita reposicionamentos de existência, resistências e gera transformações importantes. Podemos fazer algumas aproximações, a partir dos núcleos de significação do presente trabalho, com o que Moura chama de humilhação social:

A humilhação crônica, longamente sofrida pelos pobres e seus ancestrais, é efeito da desigualdade política, indica a exclusão recorrente de uma classe inteira de homens para fora do âmbito intersubjetivo da iniciativa e da palavra. Mas é também de dentro que, no humilhado, a humilhação vem atacar. A humilhação vale como uma modalidade de angústia e, nesta medida, assume internamente - como um impulso mórbido - o corpo, o gesto, a imaginação e a voz do humilhado (1998, p. 13).

As graduandas, ora mais ora menos, referem-se a experiências atravessadas pela humilhação social. Podemos destacar os primeiros contatos com a universidade; o sentimento de humilhação vivido por elas e suas famílias ao terem que apresentar uma série de documentos comprobatórios; a dificuldade de se adaptarem a um lugar completamente novo, com pouco acolhimento institucional; a chegada às aulas após os alunos pagantes; a solidão que marca os primeiros passos na universidade no bairro rico. A solidão arrefece apenas quando elas se reconhecem de imediato em seus "iguais", demais estudantes prounistas e o coletivo ProUni-se.

A experiência da humilhação social, ao mesmo tempo, convive com a potência que é ter acesso ao ensino superior, ampliando questionamentos, reflexões e itinerários de existência. Frequentemente, incomodam-se com a forma como os colegas e professores tematizam a desigualdade social de um modo, por vezes, exótico, sentindo-se desrespeitadas enquanto pobres. 
Os projetos de futuro delas são diferentes das pessoas de seus bairros periféricos, elas acabam tendo uma posição de destaque e de não identificação com o lugar de origem, o que faz com elas se sintam privilegiadas por acessar um direito que é negado à maioria. Amora e Alice são mulheres pobres que frequentam uma instituição historicamente habitada por estudantes ricos. Tecem-se assim, em seu cotidiano, as marcas de uma espécie de "não lugar", "nem tão periférica, nem tão Perdizes".

Os núcleos de significação permitiram tangenciar o tema das relações raciais. Embora a escolha das prounistas, uma negra e uma branca, não tenha levado em consideração a raça/cor das graduandas, este tema apareceu durante as conversações, revelando-se um aspecto fundamental e destacado por elas em sua trajetória acadêmica. Ambas reconhecem que existe um estereótipo de prounista, espera-se que essas graduandas sejam negras, o que é corroborado pelo fato de que, na sala de aula, a minoria negra geralmente é bolsista. Amora afirma que as pessoas sabem que ela é prounista porque ela é negra e Alice conta que as pessoas, às vezes, se chocam ao descobrir que ela é prounista por ser branca. Em sua tese de doutorado, Schucman pesquisou como a ideia de branquitude é constituída e apropriada por sujeitos brancos na cidade de São Paulo. Ela afirma que:

\section{O primeiro elemento demarcador apontado por mim} como parte do que caracteriza as divisões entre "nós brancos" e "outros não brancos" em São Paulo são os marcadores espaciais simbolizados como "lugar de branco", que estão associados diretamente a bairros, ambientes e lugares onde se acumula riqueza (Schucman, 2012, p. 108).

A universidade de elite aparece, assim, como um marcador espacial branco. O reconhecimento de seu privilégio branco, trazido por Alice, corrobora com isso. Há que se investigar melhor a temática das relações raciais, tão presente nos debates de acesso ao ensino superior e nas políticas públicas que visam a garantir o acesso e a permanência de grupos historicamente impedidos de ingressar na universidade.

As políticas de acesso e permanência ao Ensino Superior são recentes na história brasileira, o futuro dirá o lugar que esses novos atores universitários ocuparão na sociedade. Espera-se que esse trabalho contribua com a construção do compromisso social da psicologia, que ele possa potencializar o ProUni e que as prounistas possam ter aqui a experiência de reconhecimento de suas trajetórias.

\section{Contribuições dos autores}

Amaral, M. M. participou da concepção, delineamento, coleta de dados, busca e análise dos dados da pesquisa, interpretação dos resultados e redação do artigo científico. Paparelli, R. participou do delineamento, análise de dados da pesquisa, interpretação dos dados da pesquisa, interpretação dos resultados, redação do artigo científico.

\section{Conflitos de interesses}

Nenhum conflito financeiro, legal ou político envolvendo terceiros (governo, empresas e fundações privadas, etc.) foi declarado para nenhum aspecto do trabalho submetido (incluindo mas não limitando-se a subvenções e financiamentos, participação em conselho consultivo, desenho de estudo, preparação de manuscrito, análise estatística, etc.).

\section{Referências}

Aguiar, W. M. J., \& Ozella, S. (2006). Núcleos de significação como instrumento para a apreensão da constituição dos sentidos. Psicologia: Ciência e Profissão, 26(2), 222-245. doi: 10.1590/S1414-98932006000200006

Aguiar, W. M. J., \& Ozella, S. (2013). Apreensão dos sentidos: aprimorando a proposta dos núcleos de significação. Revista Brasileira de Estudos Pedagógicos, 94(236), 299-322. doi: 10.1590/S2176-66812013000100015

Aguiar, W. M. J., Soares, J. R., \& Machado, V. C. (2015). Núcleos de significação: uma proposta histórico-dialética de apreensão das significações. Cadernos de Pesquisa, 45(155), 56-75. doi: 10.1590/198053142818

Barros, A. S. X. (2015). Expansão da educação superior no Brasil: limites e possibilidades. Educação e Sociologia, 36(131), 361-390.

Bock, A. M. B. (2010). A dimensão subjetiva da desigualdade social: um estudo sobre o sentido subjetivo da vivência da desigualdade social na cidade de São Paulo (Relatório Técnico). Pontifícia Universidade Católica de São Paulo, São Paulo, SP, Brasil.

Bock, A. M. B. (2017). A Psicologia Sócio-Histórica: uma perspectiva crítica em Psicologia. In A. M. B. Bock, M. G. M. Gonçalves, \& O. Furtado (Orgs.), A Psicologia SócioHistórica: uma perspectiva crítica em Psicologia (6a ed., pp. 21-46). São Paulo, SP: Cortez. 
Carvalho, C. H. A. (2006). O PROUNI no governo Lula e o jogo político em torno do acesso ao ensino superior. Educação Sociologia, 27(96), 979-1000. doi: 10.1590/S0101$\underline{73302006000300016}$

Catani, A. M., Hey, A. P., \& Giglioli, R. S. (2006). PROUNI: democratização do acesso às instituições de Ensino Superior. Educar em Revista, 28, 125-140. doi: 10.1590/ S0104-40602006000200009

Costa, F. S. (2010). Prouni: o olhar dos estudantes beneficiários (2a ed.). São Paulo: Michelotto.

Guerra, A., Pochmann, M, \& Silva, R. A. (Orgs.) (2015). Atlas da exclusão social no Brasil: dinâmica da exclusão social na primeira década do século XXI (Vol. 2). São Paulo: Cortez.

Instituto Nacional de Estudos e Pesquisas Educacionais Anísio Teixeira (2003). Censo da Educação Superior 2003 (Resumo Técnico), Brasília: Instituto Nacional de Estudos e Pesquisas Educacionais Anísio Teixeira.

Gonçalves Filho, J. M. (1998). Humilhação social - um problema político em psicologia. Psicologia USP, 9(2), 11-67. doi: 10.1590/S0103-65641998000200002

Nascimento, A. (2016). O genocídio do negro brasileiro: processo de um racismo mascarado. São Paulo: Perspectiva.

Nogueira, M.O.G. (2013). Educação, desigualdade e políticas públicas: a subjetividade no processo de escolarização da camada pobre (Tese de doutorado). Pontifícia Universidade Católica de São Paulo, São Paulo, SP, Brasil.

Rey, F. G. (2006). Pesquisa qualitativa e subjetividade: os processos de construção da informação. São Paulo: Cengage Learning.

Sader, E. (2013). A construção da hegemonia pós-neoliberal. In E. Sader (Org.). 10 anos de governos pós-neoliberais no Brasil: Lula e Dilma (pp. 135-144). São Paulo: Boitempo; Rio de Janeiro: FLACSO Brasil.

Santos, L. N. (2013). O encontro das psicólogas com o "social" no CRAS/SUAS: entre o suposto da igualdade e a concretude da desigualdade (Dissertação de mestrado), Universidade Federal da Bahia, Salvador, BA, Brasil. Recuperado de https://repositorio.ufba.br/ri/handle/ri/12252

Schucman, L. V. (2012). Entre o "encardido", o "branco" e o "branquíssimo": Raça, hierarquia e poder na construção da branquitude paulistana (Tese de Doutorado). Instituto de Psicologia, Universidade de São Paulo, São Paulo, SP, Brasil. Recuperado de http://www.teses.usp.br/teses/ disponiveis/47/47134/tde-21052012-154521/pt-br.php

Souza, J. (2004). A gramática social da desigualdade brasileira. Revista Brasileira de Ciências Sociais, 19(54), 79-96. doi: 10.1590/S0102-69092004000100005
Souza, J. (2006). Para compreender a desigualdade brasileira. Teoria e Cultura, 1(2), 83-100. Recuperado de https:// teoriaecultura.ufjf.emnuvens.com.br/TeoriaeCultura/ article/view/1118/922 